\title{
ХИМИЧЕСКИЕ ЭЛЕМЕНТЫ И ВЕЩЕСТВА - ИНДИКАТОРЫ ЗАГРЯЗНЕНИЯ ПРИРОДНОЙ СРЕДЫ РЕСПУБЛИКИ АЛТАЙ
}

\author{
Робертус Юрий Владимирович 1 , \\ ariecol@mail.gorny.ru
}

\author{
Рихванов Леонид Петрович2, \\ rikhvanov@tpu.ru \\ 1 Институт водных и экологических проблем СО РАН, \\ Россия, 656038, г. Барнаул, ул. Молодежная, 1. \\ 2 Национальный исследовательский Томский политехнический университет, \\ Россия, 634050, г. Томск, пр. Ленина, 30.
}

\begin{abstract}
Актуальность работы обусловлена необходимостью выявления и использования в научных и практических иелях приоритетных индикаторов регионального и локального загрязнения химическими элементами и веществами компонентов природной среды на территории Республики Алтай.

Цель: установить ассоциации химических загрязнителей природной среды, изучить особенности их поведения в природных средах и стратифицированных природных образованиях, наметить приоритетные индикаторы областей и зон наложенного химического загрязнения на территории региона.

Методы: сбор, обобщение и комплексный анализ данных, содержащихся в опубликованных и фондовых материалах научных и производственных организаций по оценке эколого-геохимической обстановки на территории Республики Алтай и смежных с ней регионов, обработка систематизированных данных методами прикладной статистики.

Результаты. Охарактеризованы региональные и локальные факторы негативного воздействия на природную среду Республики Алтай. Приведены экологические последствия современного и прошлого загрязнения природной среды. Установлена высокая информативность стратифицированных природных образований при изучении прошлого загрязнения. Выделены характерные для региона основные ассоциации экотоксикантов химической природы. Раскрыты особенности загрязнения компонентов природной среды при трансграничных переносах загрязняющих веществ и при воздействии локальных источников. Выявлены природные среды, представительные для изучения наложенного загрязнения, а также химические элементы и вещества - индикаторы антропогенного загрязнения. Установлены превышающие эколого-гигиенические нормативы концентрации приоритетных индикаторов в очагах загрязнения снежного и почвенного покрова. Сделан вывод о наибольшей опасности для природной среды региона ксенобиотиков, представленных техногенными радионуклидами, компонентами ракетных топлив, хлорорганическими пестицидами.
\end{abstract}

\section{Ключевые слова:}

Республика Алтай, природная среда, источники загрязнения, химические элементы, вещества, индикаторы.

\section{Введение}

При антропогенезе в природную среду поступают разнообразные химические элементы и их соединения, зачастую обладающие токсическими свойствами. Их спектр, концентрации, химическая природа, фазовое состояние, пути поступления, устойчивость, особенности миграции и др. варьируются в очень широких пределах.

Одной из приоритетных задач геоэкологической оценки последствий антропогенной деятельности является установление зон ее текущего или прошлого негативного воздействия на компоненты природной среды. Основной используемый для этого методический подход заключается в выявлении и оконтуривании территорий, загрязненных экотоксикантами. Эта практическая задача решается путем опробования природных сред на территории наложенного (привнесенного) загрязнения, прилегающей к источнику воздействия [1-4].

Из депонентов площадного загрязнения изучается преимущественно приземная атмосфера, снеговой, почвенный и растительный покров, реже акватории и донные отложения крупных водных объектов. Для оценки загрязнения поверхностных водотоков ис- пользуются вода, донные отложения и прибрежные почвы, содержащие как транслируемые, так и закрепленные концентрации загрязняющих веществ.

Поскольку источники загрязнения (предприятия, объекты, процессы и пр.) продуцируют, как правило, широкий спектр экотоксикантов, для повышения эффективности и снижения затрат при установлении $30 \mathrm{H}$ их воздействия акцент делается на изучение особенностей распределения в «репрезентативной» природной среде одного-двух специфических для конкретного источника загрязнителей. Уровни содержания этих приоритетных химических элементов или их соединений можно рассматривать как индикаторы (маркеры) состояния депонирующих наложенное загрязнение природных сред [5-7].

Республика Алтай (РА), занимающая центральную часть Алтайской горной области, располагает уникальным природно-ресурсным потенциалом и относится к небольшому числу регионов России, слабо затронутых антропогенезом. Ещё в начале прошлого века профессор Томского технологического института Борис Петрович Вейнберг в своих записках рассуждал о Горном Алтае как о территории для получения солнечной энергии, чистой воды и отдыха чело- 
века. Но во второй половине XX в. регион испытал заметное антропогенное воздействие. Прежде всего, изменился его геохимический фон, связанный с радиоактивными выпадениями при испытаниях ядерного оружия, а также с воздействием ракетнокосмической деятельности и трансграничных переносов загрязняющих веществ с территории Казахстана.

В настоящее время в регионе отсутствуют крупные и средние промышленные предприятия и объекты тепло- и электрогенерации, т. е. главные источники экологического негатива. Основные отрасли хозяйственной деятельности в РА - животноводство, в менышей степени, лесное хозяйство, добыча полезных ископаемых и рекреация - оказывают в основном незначительное воздействие на природную среду, сохранившую на основной части региона свой первозданный облик.
Тем не менее имеющиеся геоэкологические данные свидетельствуют о наличии текущего и прошлого техногенного загрязнения на территории РА, основные факторы которого делятся на две группы - региональные и локальные (табл. 1). Первые из них обусловлены трансграничными переносами загрязняющих веществ, вторые местными источниками относительно узкого спектра загрязнения, проявленного главным образом в пределах хозяйственно-селитебных территорий республики.

Уровень негативного воздействия на природную среду региона локальных источников преимущественно низкий, региональных источников - от низкого до высокого (табл. 1). Основные экологические последствия их воздействия проявлены в виде разномасштабных областей и очагов неравномерно распределенного на территории РА наложенного химического и радиохимического загрязнения (рис. 1).

Таблица 1. Основные источники негативного воздействия на природную среду РА

Table 1. Main sources of negative impact on the natural environment of the Altay Republic

\begin{tabular}{|c|c|c|c|c|}
\hline $\begin{array}{l}\text { Воздействие } \\
\text { Eexposure }\end{array}$ & \multicolumn{2}{|c|}{$\begin{array}{l}\text { Источники воздействия } \\
\text { Sources of exposure }\end{array}$} & $\begin{array}{l}\text { Уровень } \\
\text { Level }\end{array}$ & $\begin{array}{l}\text { Экологические последствия } \\
\text { Environmental consequences }\end{array}$ \\
\hline \multirow{3}{*}{$\begin{array}{l}\text { Региональное } \\
\text { Regional }\end{array}$} & \multicolumn{2}{|c|}{$\begin{array}{c}\text { Ядерные полигоны } \\
\text { Nuclear polygon }\end{array}$} & $\begin{array}{l}\text { Высокий } \\
\text { Higt }\end{array}$ & $\begin{array}{l}\text { Очаги радиоактивного загрязнения } \\
\text { Sites of radioactive contamination }\end{array}$ \\
\hline & \multicolumn{2}{|c|}{$\begin{array}{l}\text { Космодром «Байконур» } \\
\text { The Cosmodrome Baikonur }\end{array}$} & $\begin{array}{l}\text { Средний } \\
\text { Average }\end{array}$ & $\begin{array}{c}\text { Захламление ОЧ РН, загрязнение КРТ } \\
\text { Littering with SP LV, contamination with RFC }\end{array}$ \\
\hline & \multicolumn{2}{|c|}{$\begin{array}{c}\text { Трансграничные переносы } \\
\text { Transboundary transport }\end{array}$} & $\begin{array}{l}\text { Низкий } \\
\text { Low }\end{array}$ & $\begin{array}{l}\text { Привнос ТМ, ПН, кислотных осадков } \\
\text { Introduction of HM, ID, acid precipitation }\end{array}$ \\
\hline \multirow{8}{*}{$\begin{array}{l}\text { Локальное } \\
\text { Local }\end{array}$} & \multirow{5}{*}{ 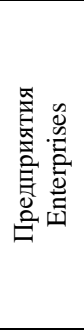 } & $\begin{array}{l}\text { промышленные* } \\
\text { industrial* }\end{array}$ & $\begin{array}{l}\text { Низкий } \\
\text { Low }\end{array}$ & $\begin{array}{c}\text { Очаги загрязнения TM, OB, AM, ПАВ } \\
\text { Sites of contamination with HM,OS,MN, SAS }\end{array}$ \\
\hline & & $\begin{array}{l}\text { горнодобывающие } \\
\text { mining }\end{array}$ & $\begin{array}{l}\text { Средний } \\
\text { Average }\end{array}$ & $\begin{array}{c}\text { Очаги загрязнения ТМ, XP, НП } \\
\text { Sites of contamination with HM, CR, PP }\end{array}$ \\
\hline & & $\begin{array}{l}\text { деревообработки } \\
\text { woodworking }\end{array}$ & $\begin{array}{l}\text { Низкий } \\
\text { Low }\end{array}$ & $\begin{array}{l}\text { Захламление, загрязнение OB, НП } \\
\text { Littering, contamination with OS, PP } \\
\end{array}$ \\
\hline & & $\begin{array}{l}\text { сельского хозяйства } \\
\text { agriculture }\end{array}$ & $\begin{array}{l}\text { Низкий } \\
\text { Low }\end{array}$ & $\begin{array}{c}\text { Очаги загрязнения OB, AM, ФФ, ХОП } \\
\text { Sites of contamination with OS, MN, PhPh, OCP }\end{array}$ \\
\hline & & $\begin{array}{c}\text { теплоэнергетики } \\
\text { power industry }\end{array}$ & $\begin{array}{l}\text { Низкий } \\
\text { Low }\end{array}$ & $\begin{array}{c}\text { Очаги загрязнения TM, ПН, (C,N,S)On, } \\
\text { Sites of contamination with HM,ID, (C,N,S)On }\end{array}$ \\
\hline & \multicolumn{2}{|c|}{$\begin{array}{l}\text { Селитебные зоны } \\
\text { Residential areas }\end{array}$} & $\begin{array}{l}\text { Низкий } \\
\text { Low }\end{array}$ & $\begin{array}{c}\text { Очаги загрязнения TM, OB, НП, ПАВ } \\
\text { Sites of contamination with HM,OS,PP,SAS }\end{array}$ \\
\hline & \multicolumn{2}{|c|}{$\begin{array}{c}\text { Автотранспорт } \\
\text { Road transport }\end{array}$} & $\begin{array}{l}\text { Низкий } \\
\text { Low }\end{array}$ & $\begin{array}{c}\text { Очаги и потоки загрязнения НП, ТМ } \\
\text { Sites and streams of pollution with PP, HM }\end{array}$ \\
\hline & \multicolumn{2}{|c|}{$\begin{array}{c}\text { Рекреация и туризм } \\
\text { Recreation and tourism } \\
\end{array}$} & $\begin{array}{l}\text { Низкий } \\
\text { Low }\end{array}$ & $\begin{array}{c}\text { Очаги загрязнения НП, OB, P, N } \\
\text { Sites of contamination with PP, OS, P, N }\end{array}$ \\
\hline
\end{tabular}

*- предприятия легкой и пищевой промышленности, ТМ - тяжелые металль, ХР - химические реагенты, КРТ компоненты ракетных топлив, ОВ - органические вещуества (С, УГВ, феноль и др.), АМ - азот минеральный, ФФфосфаты, ХОП - хлорорганические пестициды, НП - нефтепродукты, ПАВ - поверхностно-активные вещества, ПН- пьль неорганическая.

*- enterprises of light and food industry, HM - heavy metal, CR - chemical reagent, RFC - rocket fuel components, OS organic substances ( $C$, hydrocarbons, phenols, etc.), MN - mineral nitrogen, PhPh - phosphates, OCP - organochlorine pesticides, $P P$ - petroleum product, SAS - surface-active substances, ID - inorganic dust.

\section{Информационные материаль}

Фактический материал для подготовки настоящей статьи получен авторами при многолетнем изучении особенностей проявления вышеотмеченных региональных и локальных факторов загрязнения природной среды Республики Алтай (глобальные выпадения в настоящей статье не рассматриваются).

Информация по трансграничным переносам загрязняющих веществ на территорию Алтая получена в последние годы при изучении выпадений экотоксикантов в депонирующих средах, а также в стратифицированных природных образованиях (СПО) - лед- никах, донных отложениях водоемов, годичных кольцах деревьев и др. [8-12], а также в солевых отложениях (накипи) подземных вод [13].

В 1990-е гг. в рамках комплексного изучения медико-экологических последствий испытаний ядерных устройств на Семипалатинском полигоне были получены основные данные по радиоактивному загрязнению региона [14]. В период 1990-2000-е гг. при экологической паспортизации районов падения (РП) отделяющихся частей ракет-носителей (ОЧ РН) и при сопровождении их пусков собран материал по экологическим последствиям ракетно-космической деятельности (РКД) на территории РА [15]. 

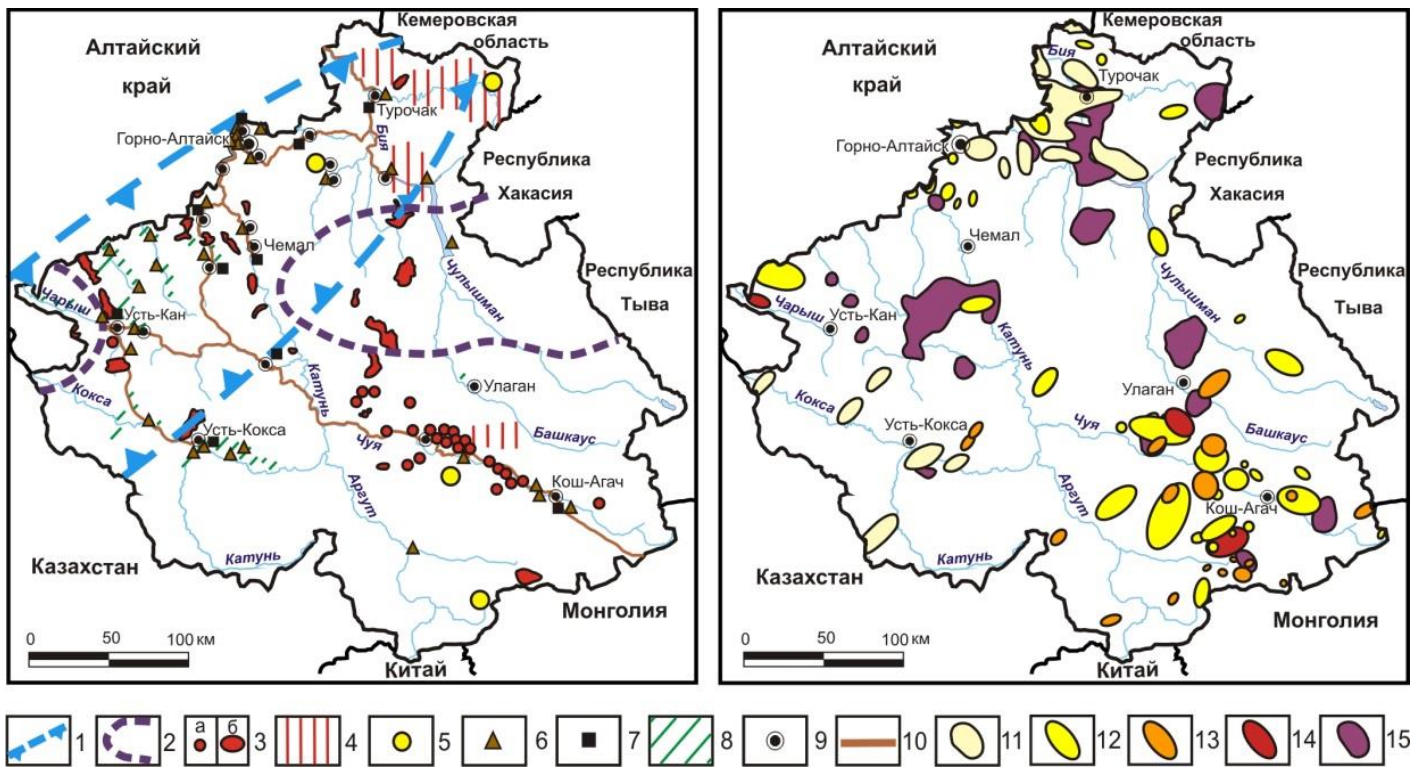

Pис. 1. Схемы химического (слева) и радиохимического загрязнения Республики Алтай: 1 - область трансграничного переноса выбросов предприятий ВКО; 2 - области размещения фрагментов ракет-носителей; 3 - месторождения и проявления ртути (а), литохимические и шлиховые ореолы ее рассеяния (б); 4 - площади ртутного загрязнения; 5 - участки загрязненные горнодобывающими предприятиями; 6 - очаги загрязнения хлорорганическими пестицидами; 7 - полигоны ТКО; 8 - пахотные земли; 9 - основные сельскохозяйственноселитебные объекты; 10 - основные автодороги; 11-14 - очаги прошлого радиоактивного загрязнения по данным аэрогамма-съемок (11), 12-14 - измерений МЭД до 100 мкР/час (12), 100-1000 мкР/час (13), более

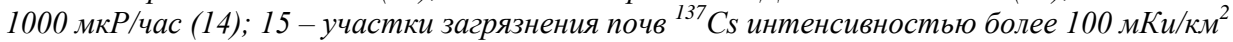

Fig. 1. Schemes of chemical (left) and radiochemical pollution of the Altai Republic: 1 - area of cross-border transfer of emissions of East Kazakhstan region enterprises; 2 - areas of placement of fragments of launch vehicles; 3 - deposits and shows of mercury (a), lithochemical and heavy concentrate areas of its scattering (6); 4 - areas of mercury pollution; 5 - areas contaminated by mining companies; 6 - sites contaminated by organochlorine pesticides; 7 solid municipal waste landfills; 8 - arable lands; 9 - main agricultural and residential objects; 10 - main roads; 1114 - the last sites of radioactive contamination according aerogamma shots (11), 12-14 - measurements of equivalent dose rate up to $100 \mathrm{mcR} /$ hour (12), 100-1000 mcR/hour (13), more than $1000 \mathrm{mcR} / \mathrm{hour}$ (14); 15 contamination of ${ }^{137} \mathrm{Cs}$ soil areas with an intensity of more than $100 \mathrm{mCi} / \mathrm{km}^{2}$

Фактический материал по экогеохимическим последствиям воздействия локальных источников взят главным образом из фондовых отчетов научных и производственных организаций по оценке экологической обстановки в населенных пунктах и на производственных объектах РА. Кроме отмеченного были использованы данные из публикаций по теме проведенного обобщения.

\section{Результаты и их обсуждение}

Основные негативные последствия воздействия антропогенных источников на территории РА заключаются в формировании различных по размерам, структуре и интенсивности очагов наложенного загрязнения компонентов природной среды минеральными и органическими химическими веществами природного и искусственного происхождения. К первым из них относятся химические элементы и большинство их природных соединений, к группе ксенобиотиков - техногенные радионуклиды $\left({ }^{137} \mathrm{Cs},{ }^{90} \mathrm{Sr}\right.$, ${ }^{239,240} \mathrm{Pu}$ и др.); компоненты ракетных топлив (КРТ) и их производные - 1,1-диметилгидразин (НДМГ), тетраоксид азота (АТ), тетраметилтетразен (ТМТ), углеводородные топлива (Т-1, РТ-1, синтин); используемые в сельском хозяйстве ядохимикаты, особенно хлорорганические пестициды (ХОП) ДДТ и ГХЦГ, а также флотореагенты, нефтепродукты, полиароматические углеводороды (в т. ч. бенз/а/пирен), различные поверхностно-активные вещества и др.

Экологическое значение как природных, так и искусственных экотоксикантов, в т. ч. их опасность для природной среды и степень токсичности для живых организмов, варьируется в широком диапазоне и зависит, помимо прочего, от их стабильности и подвижности в природных условиях РА. С учетом этого в регионе к наиболее опасным химическим загрязнителям природной среды следует отнести ртуть, хлорорганические пестициды, отдельные производные КРТ, а также долгоживущие техногенные радионуклиды (ТРН).

Наложенное антропогенное загрязнение отличается от его природного эквивалента (несоответствия эколого-гигиеническим нормативам), как правило, повышенным и аномально высоким содержанием загрязняющих веществ, их расширенным спектром и превалирующим поступлением в воздушный бассейн и на рельеф местности. Его основными реципиентами в условиях Алтайской горной страны является снежный и почвенно-растительный покров, частично литогенный субстрат, трансляторами - ветровой перенос, плоскостной смыв и поверхностный сток. При этом абиотическими депонентами загрязнения высту- 
пают почвы, почвообразующие породы, вода и донные отложения водоемов, а биотическими - травянистые, кустарниковые и древесные растения, растительный опад, лесная подстилка, мхи, лишайники и пр.

Приземная атмосфера, снежный покров, поверхностные воды и вегетативные органы растений выступают в основном в роли депонентов современного загрязнения, а донные отложения и почвы - современного (верхние горизонты) и прошлого поступления загрязняющих веществ. В зависимости от особенностей проявления загрязнения информативность этих природных сред как своеобразных тест-объектов загрязненности территории варьируется от низкой до высоко репрезентативной.

Региональные источники загрязнения. К превалирующим факторам привнесенного площадного загрязнения природной среды РА относятся: радиоактивное загрязнение при наземных и воздушных взрывах ядерных устройств на Семипалатинском испытательном полигоне (СИП) в 1949-1962 гг. и, в меньшей степени, на полигоне Лобнор (1970-1990-е гг.); запуски ракетоносителей $(\mathrm{PH})$ с космодрома «Байконур» (с конца 1950 гг. по настоящее время); многолетняя деятельность металлургических предприятий Восточно-Казахстанской области (ВКО), расположенных в городах Усть-Каменогорск и Риддер.

Радиоактивное загрязнение региона обусловлено в основном прошлыми локальными атмосферными выпадениями техногенных радионуклидов (ТРН) при прохождении радиоактивных облаков от воздушных и наземных ядерных взрывов. По разным данным, на территорию РА оказали влияние от 22 до 40 взрывов на СИП [14]. Данные по воздействию испытаний на полигоне Лобнор отсутствуют, однако их следы отчетливо проявлены в стратифицированных природных образованиях (СПО) (рис. 2).

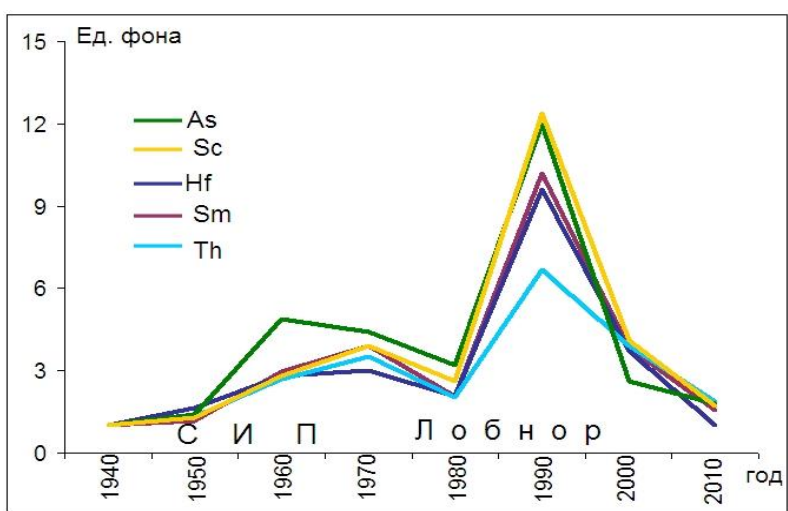

Pис. 2. Коэффициенты концентрации элементов в золе годичных колеи лиственнииы в с. Кайсын (слева), то же йода и ванадия в талой воде ледника Большой Актру (справа)

Fig. 2. Coefficients of element concentration in the ash of larch annual rings in $v$. Kaisyn (left), the same iodine and vanadium in the meltwater of the Big Aktru glacier (right)

По архивным геологическим материалам, в 1950-1960-е гг. на территории региона установлено более 70 случаев аномальных повышений радиационного фона интенсивностью до первых тысяч мкР/час от радиоактивных следов 18 взрывов и выявлено около 80 разных по размерам и интенсивности очагов локального мозаично-очагового радиоактивного загрязнения почвенного покрова. Необходимо отметить, что современный уровень и запасы остаточного загрязнения почвенного покрова региона ${ }^{137} \mathrm{Cs}$ и ${ }^{90} \mathrm{Sr}$ в среднем в два раза выше их регионального фона (величины глобальных выпадений), а уровень загрязнении ${ }^{239,240} \mathrm{Pu}$ выше его в 5 раз.

Основные периоды взрывов на СИП и полигоне Лобнор отчетливо проявлены в разных СПО, в частности в годичных кольцах деревьев и в ледниках. Кроме остаточных концентраций долгоживущих радионуклидов, тория, урана, РЗЭ, характерным индикатором прошлого радиоактивного загрязнения служит аномально повышенное до 30 единиц фона содержание йода (продукт распада короткоживущего изотопа йод-131) в талой воде ледника Большой Актру (рис. 2) [11].

Другим значимым в плане негативных экологических последствий фактором регионального воздействия является многолетняя ракетно-космическая деятельность. На территории РА расположен ряд районов падения отделяющихся частей ракетносителей «Союз», «Протон» и «Зенит», запускаемых с космодрома «Байконур» (около 630 пусков). Расчетная площадь всех РП 5,3 тыс. км², фактическая площадь распространения ОЧ РН составляет 23 тыс. км (четверть территории региона).

Основные создаваемые РКД экологические проблемы связаны с замусориванием фрагментами ОЧ РН значительных по площади и уникальных по природно-ресурсному потенциалу территорий, в том числе одного из старейших в стране Алтайского биосферного заповедника. Более значимые, но недостаточно изученные последствия связаны с аэрогенным загрязнением природной среды токсичными компонентами ракетных топлив (1,1-диметилгидразин, тетраоксид азота) и их производными, а также с непосредственным воздействием их аэрозолей на биотические среды и объекты [15].

Так, одно из слабо изученных последствий пусков PH «Протон-К», а в дальнейшем РН «Протон-М», выражается в загрязнении нитритами, нитратами, ионом аммония (конечными продуктами превращения КРТ) природных сред в РП и на прилегающих к ним территориях. В конечном итоге это приводит к подкислению снежного и почвенного покрова, которое проявляется пониженными значениями их $\mathrm{PH}$ (рис. 3). Можно предполагать, что многолетнее воздействие РКД способствует усилению кислотности почв на подверженной ей территории региона.

Более длительное воздействие на территорию Алтая оказывают слабо изученные трансграничные переносы загрязнителей, содержащихся в выбросах свинцово-цинковых заводов Усть-Каменогорска и Риддера - основных центров цветной металлургии в Восточно-Казахстанской области (ВКО). Ежегодно они выбрасывают в атмосферу более 60 тысяч тонн 
загрязнителей, среди которых преобладают диоксид серы, оксиды азота и пылеватые частицы, содержащие $\mathrm{Zn}, \mathrm{Pb}, \mathrm{Cu}, \mathrm{As}, \mathrm{Se}, \mathrm{Cd}, \mathrm{Tl}$ и др. Следы их выбросов отчетливо проявлены в регионе в природных планшетах атмосферных выпадений, в частности, таллия в почвах [16], а также в СПО (годичные кольца деревьев, донные осадки, ледники и др.).

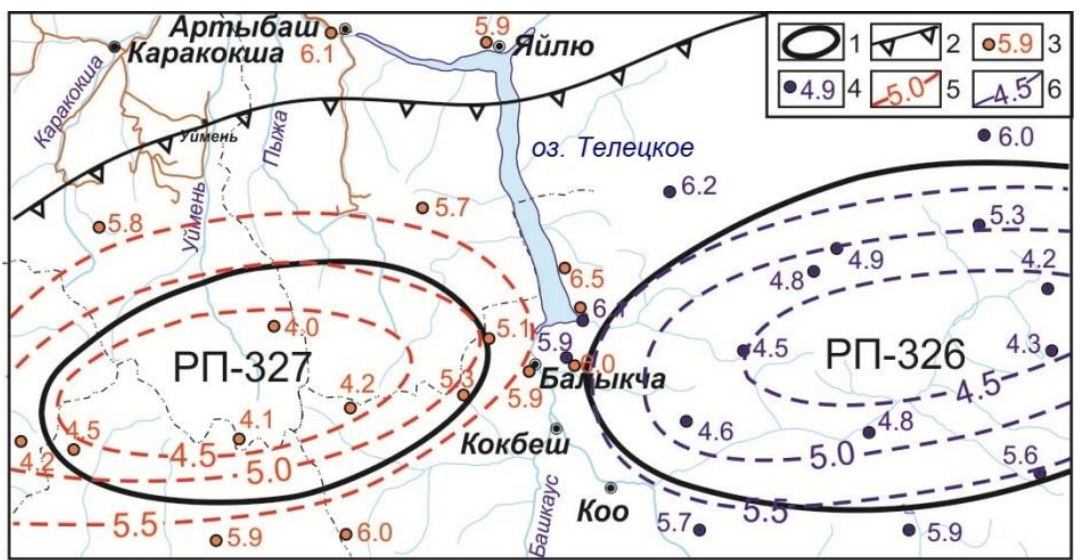

Pис. 3. Подкисление снежного покрова и почв районов падения РН «Протон» (2002 г): 1 - районы падения; 2 - область размещения фрагментов ОЧ РН; 3, 4 - значения рН почв (3), талой воды (4); 5, 6-изолинии рН почв (5), талой воды (6)

Fig. 3. Acidification of snow cover and soil in the areas where $L V$ «Proton» fall (2002): 1 -fall areas; 2 - area of placement of fragments of SP LV; 3, 4-the pH value of soil (3), melt water (4); 5, 6-contours of pH of soils (5), melt water (6)

В частности, в снежном покрове сопредельной с ВКО территории РА авторами выявлен крупный ореол слабокислотных выпадений сульфатов, соединений азота и ассоциации элементов полиметаллических руд, проявленных на фоне пониженных значений $\mathrm{pH}$ [9] Этот ореол проявлен также в элементном составе лишайника на камне Rhizocarpon geographicum и в листьях тополя черного (Populus nigra L.).

Особенности нахождения бериллия в талой воде ледника Бол. Актру (отсутствие значимых связей и отрицательные связи с основными элементами полиметаллических руд) позволяют говорить о его «самостоятельном» поступлении на территорию РА. Источником бериллия предположительно является Ульбинский металлургический завод (г. УстьКаменогорск), а механизмом поступления - трансграничный перенос воздушных масс загрязненных выбросами этого предприятия.

Предварительно установлено, что через территорию ВКО на Алтай постоянно поступает тонкая пылеватая фракция, представленная в снеговой пыли алюмосиликатными частицами, состоящими из основных элементов горных пород ( $\mathrm{Si}, \mathrm{Al}, \mathrm{Ca}, \mathrm{Na}, \mathrm{K}, \mathrm{Fe}$ и др.). Они предположительно поступают с трансграничными переносами пылеаэрозолей из Средней Азии и переносятся на значительно большие расстояния, чем рудные частицы металлургических предприятий ВКО.

Необходимо отметить, что в СПО региона проявлены и другие загрязняющие вещества, переносимые на территорию РА, в частности, пыльными бурями в западной части Степного Алтая. Их индикаторами в годичных кольцах лиственницы и в листьях тополя в Западном Алтае служат аномально повышенные концентрации (до 35 раз, в среднем в 5,5 раз) тесно связанных между собой галогенов (бром, йод) и щелочных металлов (натрий, калий, цезий, рубидий), по- ступающих с соленых озер и засоленных почв Кулундинской впадины [9].

Характер распределения ванадия и его спутников (селен, сера, бром и др.) в талой воде ледника Большой Актру позволяет предполагать, что они являются индикаторами переносов на территорию РА продуктов сгорания попутного нефтяного газа (ПНГ) на разведываемых и эксплуатируемых нефтяных месторождениях Западной Сибири [11]. Так, прогрессирующе нарастающее содержание ванадия в отложениях ледника Большой Актру за последние полвека увеличилось в 25 раз (рис. 2). Трансграничный перенос продуктов сгорания ПНГ предположительно происходит при поступлении холодных арктических воздушных масс в зимний период.

Имеющиеся данные по проявлению загрязняющих веществ в депонирующих их природных средах и СПО на территории РА позволяют выделить в качестве индикаторов трансграничных поступлений на территорию региона следующие химические элементы и их природные и искусственные соединения, в том числе радионуклиды (табл. 2). Среди них выделены приоритетные индикаторы перечисленных выше трансграничных переносов, а также природные среды и образования, которые целесообразно использовать при изучении и оценке параметров привнесенного загрязнения территории региона.

Источники локального загрязнения представлены в РА небольшими предприятиями по добыче полезных ископаемых (в основном россыпное золото и стройматериалы), легкой и пищевой промышленности, деревообработки, сельского хозяйства и др. Специфическое загрязнение оказывают также автотранспорт, объекты малой теплоэнергетики (угольные котельные), хозяйственно-селитебные зоны и объекты инфраструктуры туризма. 
Таблица 2. Индикаторы переносов загрязняющих веществ (ЗВ) на территорию РА

Table 2. Indicators of transport of pollutants to the territory of the Altay Republic

\begin{tabular}{|c|c|c|c|c|}
\hline $\begin{array}{c}\text { Источники ЗВ } \\
\text { Sources of pollutants }\end{array}$ & $\begin{array}{c}\text { Факторы } \\
\text { переноса ЗВ } \\
\text { Pollutant transport } \\
\text { factors } \\
\end{array}$ & $\begin{array}{l}\text { Переносимые 3В } \\
\text { Transportable } \\
\text { pollutants }\end{array}$ & $\begin{array}{c}\text { Природные среды - } \\
\text { депоненты 3В } \\
\text { Natural environments - } \\
\text { depositors of pollutants } \\
\end{array}$ & $\begin{array}{c}\text { Индикаторы } \\
\text { загрязнения } \\
\text { Indicators of pollution }\end{array}$ \\
\hline $\begin{array}{c}\text { Ядерные полигоны: } \\
\text { СИП, Лобнор } \\
\text { Nuclear test sites: SPG, } \\
\text { Lobnor }\end{array}$ & $\begin{array}{c}\text { Радиоактивные } \\
\text { облака } \\
\text { Radioactive clouds }\end{array}$ & $\begin{array}{c}\text { Техногенные } \\
\text { Радионуклиды } \\
\text { Technogenic } \\
\text { radionuclides }\end{array}$ & $\begin{array}{c}\text { Почва, донные } \\
\text { отложения, СПО } \\
\text { Soil, bottom sediments, } \\
\text { SNF }\end{array}$ & ${ }^{137} \mathrm{Cs},{ }^{90} \mathrm{Sr},{ }^{240} \mathbf{P u} \mathbf{J}$, P3Э \\
\hline $\begin{array}{c}\text { Космодром «Байконур» } \\
\text { The Cosmodrome } \\
\text { «Baikonur» }\end{array}$ & $\begin{array}{c}\text { Осадки, } \\
\text { гидроаэрозоли } \\
\text { Rainfall, hydroaerosols }\end{array}$ & $\begin{array}{c}\text { КРТ и их } \\
\text { производные } \\
\text { RFC and their } \\
\text { derivatives }\end{array}$ & $\begin{array}{c}\text { Снег, почва, } \\
\text { растения, вода } \\
\text { Snow, soil, plants, } \\
\text { water } \\
\end{array}$ & $\begin{array}{l}\text { НДМГ, ТМТ, } \mathrm{NO}_{2}^{-} \\
\mathbf{N H}_{\mathbf{3}}, \mathrm{NO}_{3}^{-}, \mathbf{T}-\mathbf{1}, \mathbf{p H}\end{array}$ \\
\hline $\begin{array}{c}\text { Предприятия ВКО: АО } \\
\text { «УМЗ», ТОО «Казцинк» } \\
\text { Enterprises of East } \\
\text { Kazakhstan: «UMP», } \\
\text { «Kazzinc» }\end{array}$ & $\begin{array}{c}\text { Кислотные осадки, } \\
\text { пылеаэрозоли } \\
\text { Acid rainfall, dust } \\
\text { aerosols }\end{array}$ & $\begin{array}{c}\text { TM, оксиды } \\
\text { азота, серы } \\
\text { HM, oxides of } \\
\text { nitrogen, sulfur }\end{array}$ & $\begin{array}{c}\text { Снег, почва, } \\
\text { растения, CПО } \\
\text { Snow, soil, plants, SNF }\end{array}$ & $\begin{array}{l}\text { Be, Cu, Zn, Pb, Cd, U } \\
\text { As, Sb, Se, Tl, Hg, pH }\end{array}$ \\
\hline $\begin{array}{c}\text { Пыльные бури в Кулун- } \\
\text { динской степи } \\
\text { Dust storms in the kulundin } \\
\text { steppe }\end{array}$ & $\begin{array}{c}\text { Пылевые облака, } \\
\text { пылеаэрозоли } \\
\text { Dust clouds, dust } \\
\text { aerosols } \\
\end{array}$ & $\begin{array}{c}\text { Щёлочи, } \\
\text { галогены } \\
\text { Alkalis, halogens }\end{array}$ & $\begin{array}{l}\text { Почва, растения, } \\
\text { CПO } \\
\text { Soil, plants, SNF }\end{array}$ & $\mathbf{N a}^{+}, \mathrm{Cs}, \mathbf{B r}, \mathrm{J}, \mathrm{Cl}$ \\
\hline $\begin{array}{c}\text { Нефтепромыслы } \\
\text { Западной Сибири } \\
\text { Oil fields in Western Siberia }\end{array}$ & $\begin{array}{c}\text { Осадки, } \\
\text { пылеаэрозоли } \\
\text { Rainfall, } \\
\text { dust aerosols }\end{array}$ & $\begin{array}{c}\text { Продукты сгорания } \\
\text { ПНГ } \\
\text { Combustion products } \\
\text { of APG }\end{array}$ & $\begin{array}{c}\text { Почва, СПО } \\
\text { Soil, SNF }\end{array}$ & $\mathbf{У Г В ~}, \mathrm{CH}_{4}, \mathbf{V}, \mathbf{S e}$ \\
\hline
\end{tabular}

Выделены приоритетные депонирующие загрязнение природные среды и индикаторы загрязнения.

Priority depositing environmental pollution and its indicators.

Основными факторами локального загрязнения компонентов природной среды являются выбросы, сбросы и размещение опасных производственных и коммунальных отходов. Наиболее наглядно эти факторы проявлены для действующих и ранее функционировавших в регионе горнодобывающих предприятий (ГДП), для которых основным источником экотоксикантов являются технологические воды обогатительных фабрик, размещаемые в хвостохранилищах и прудках-отстойниках и поступающие в природную среду при их испарении, фильтрации, утечках и сбросах. В меньшей степени негативное воздействие на компоненты природной среды оказывают выбросы (кроме Акташского ГМП), отходы добычи и обогащения [17].

Следовательно, в общем виде степень опасного воздействия ГДП на компоненты природной среды зависит от сочетанного эффекта вещественного состава перерабатываемых полезных ископаемых, применяемых технологий, а также от уровня экологических последствий их выбросов, сбросов и размещения отходов.

Установлено [17], что технологические воды (растворы) ГДП наследуют особенности химического состава перерабатываемых ископаемых и применяемых реагентов. Их специфику предлагается оценивать путем сравнения с составом используемых природных вод. Показатели техногенной добавки загрязняющих веществ в исходные воды для технологических вод ГДП варьируются в больших пределах - от первых единиц до первых тысяч. Рассчитанные значения этого показателя показывают, что среди ГДП наиболее «техногенными» и, следовательно, максимально токсичными являются технологические растворы бывшей установки кучного выщелачивания золота (УКВ) рудника «Веселый», обогатительной фабрики рудника «Калгуты», металлозавода Акташского ГМП, а наименее загрязненными - воды ЗИФ рудника «Веселый».

Характерно, что химические элементы и вещества - «лидеры» техногенного вклада ГДП - являются приоритетными индикаторами загрязнения природной среды [18]. К ним относятся основные элементы руд $(\mathrm{Hg}, \mathrm{Mo}, \mathrm{W}, \mathrm{Cu}, \mathrm{Zn} \mathrm{As})$ и компоненты используемых химических реагентов - цианиды, нитриты, хлориды, сульфаты и др. (табл. 3).

В отличие от состава технологических вод (растворов) ГДП, коммунальные стоки на примере сбросных вод очистных сооружений и ливневой канализации г. Горно-Алтайска характеризуются иным техногенным вкладом в загрязнение природных вод, в частности, преобладанием соединений азота, фосфатов, хлоридов, нефтепродуктов [19].

Основным негативным следствием гидравлического способа разработки россыпей золота на территории РА является перманентное загрязнение водотоков глинисто-иловым материалом, а его индикатором - взвешенные вещества, нефтепродукты от используемой техники и зачастую ртуть при отработке старых россыпей.

Эпизодическая разработка в 1990-х гг. ТалдуДюргунского буроугольного месторождения показала, что кроме повышенных концентраций таллия, кадмия, никеля, ванадия, цинка и других элементов, заметное негативное воздействие на природную среду оказывают также присутствующие в углях соединения азота и минералы серы (гипс, самородная сера). Отметим, что минимальное воздействие на природную среду оказывает добыча природных стройматериалов карьерным способом, основной загрязнитель которой представлен нефтепродуктами (табл. 4). 
Таблица 3. Техногенный вклад в загрязнение промышиленных вод и коммунальных стоков

Table 3. Anthropogenic contribution to the pollution of industrial water and municipal effluents

\begin{tabular}{|c|c|}
\hline $\begin{array}{l}\text { Предприятия } \\
\text { Enterprises }\end{array}$ & $\begin{array}{l}\text { Геохимический ряд техногенной составляющей загрязнения (ед. фона) } \\
\text { Geochemical line of the technogenic component of pollution (background units) }\end{array}$ \\
\hline \multicolumn{2}{|c|}{$\begin{array}{c}\text { Технологические воды действующих и ранее функционировавших ГДП } \\
\text { Process waters of existing and previously functioning mining enterprises }\end{array}$} \\
\hline $\begin{array}{l}\text { Рудник «Веселый» (ЗИФ) } \\
\text { Mine «Vesely» }\end{array}$ & $\mathrm{NO}_{2}^{-}(\mathbf{2 4})-\mathrm{Cu}(\mathbf{1 0 , 5})-\mathrm{Fe}(4,3)-\mathrm{Hg}(3,5)-\mathrm{Cl}^{-}, \mathrm{NO}_{3}^{-}(2,8)$ \\
\hline $\begin{array}{l}\text { Рудник «Веселый» (УКВ) } \\
\text { Mine «Vesely» (HLI) }\end{array}$ & $\mathrm{CN}^{-}(>10000)-\mathrm{Cu}(6240)-\mathrm{Zn}(2000)-\mathrm{Cl}, \mathrm{SO}_{4}^{-} \mathrm{NO}_{2}^{-}(85)-\mathrm{Na}(62)$ \\
\hline $\begin{array}{c}\text { Рудник «Калгуты» } \\
\text { Mine «Kalguty» }\end{array}$ & $\mathrm{Mo}(4620)-\mathrm{NO}_{2}^{-}(\mathbf{7 8 0})-\mathrm{W}(200)-\mathrm{Cu}(100)-\mathrm{SO}_{4}^{-}{ }^{-}(43)-\mathrm{Fe}(8)$ \\
\hline $\begin{array}{l}\text { Акташское ГМП } \\
\text { Aktash MME }\end{array}$ & $\mathrm{Hg}(\mathbf{2 3 2 0})-\mathrm{NO}_{2}{ }^{-}, \mathrm{Zn}(\mathbf{5 0})-\mathrm{Cu}, \mathbf{A s}, \mathrm{Sb}(\mathbf{3 0})-\mathrm{Cl}^{-}(12)-\mathrm{SO}_{4}^{-}(6,5)$ \\
\hline \multicolumn{2}{|c|}{$\begin{array}{c}\text { Сбросные воды хозяйственно-селитебной агломерации г. Горно-Алтайска } \\
\text { Waste water of the economic and residential agglomeration of Gorno-Altaisk }\end{array}$} \\
\hline $\begin{array}{l}\text { Очистные сооружения } \\
\text { Treatment facilities }\end{array}$ & $\mathrm{NO}_{2}^{-}{ }^{-}(239)-\mathrm{PO}_{4}{ }^{3-}(94)-\mathrm{NH}_{4}{ }^{+}(31)-\mathrm{Cl}^{-}(14)-\mathrm{NO}_{3}{ }^{-}(10)$ \\
\hline $\begin{array}{l}\text { Ливневая канализация } \\
\text { Storm water drain }\end{array}$ & $\mathbf{N O}_{2}^{-}(\mathbf{7 5})-\mathbf{H I}(40)-\mathrm{Ca}(17)-\mathrm{PO}_{4}{ }^{3-}(14,5)-\mathrm{Cl}^{-}(7,4)-\mathrm{NO}_{3}^{-}(4,3)$ \\
\hline
\end{tabular}

Примечание: выделены основные загрязнители технологических и сбросных вод.

Note: the main pollutants of process and waste water are identified.

Таблица 4. Элементы (вещества) - индикаторы переработки полезных ископаемых

Table 4. Elements (substances) - indicators of mineral processing

\begin{tabular}{|c|c|c|c|}
\hline $\begin{array}{c}\text { Месторождения } \\
\text { (полезные ископаемые) } \\
\text { Deposits (minerals) }\end{array}$ & $\begin{array}{c}\text { Технологии } \\
\text { обогащения, передела } \\
\text { Technologies for enrichment, and } \\
\text { conversion }\end{array}$ & $\begin{array}{c}\text { Основные } \\
\text { загрязнители } \\
\text { Main pollutants }\end{array}$ & $\begin{array}{c}\text { Индикаторы } \\
\text { химического загрязнения } \\
\text { Indicators of chemical pollution }\end{array}$ \\
\hline \multirow{2}{*}{$\begin{array}{c}\text { Синюхинское } \\
\text { (золото коренное) } \\
\text { Sinyukhinskoe } \\
\text { (indigenous gold) } \\
\end{array}$} & $\begin{array}{c}\text { Амальгамация, флотация } \\
\text { Amalgamation, flotation }\end{array}$ & ТМ, ФР, фенолы & $\mathbf{H g}, \mathbf{C u}, \mathrm{Bi}, \mathrm{Ag}$, ФР \\
\hline & $\begin{array}{c}\text { Кучное выщелачивание } \\
\text { Heap leaching } \\
\end{array}$ & $\mathrm{NaCN}, \mathrm{NaOH}, \mathrm{Ca}(\mathrm{ClO})_{2}$ & 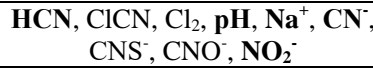 \\
\hline $\begin{array}{c}\text { Бассейн р. Каурчак } \\
\text { (золото россыпное) } \\
\text { Basin of the Yurchak river } \\
\text { (placer gold) }\end{array}$ & $\begin{array}{c}\text { Гравитация, } \\
\text { амальгамация } \\
\text { Gravity, amalgamation }\end{array}$ & $\begin{array}{c}\text { НП, взвешенные вещества, } \\
\text { ртуть } \\
\text { PP, suspended substances, } \\
\text { mercury }\end{array}$ & $\begin{array}{l}\mathrm{Hg}, \mathrm{H \Pi} \\
\mathrm{Hg}, \mathrm{PP}\end{array}$ \\
\hline $\begin{array}{c}\text { Калгутинское } \\
\text { (редкие металлы) } \\
\text { Kalgutinskoe (rare metal) }\end{array}$ & $\begin{array}{l}\text { Гравитация, флотация } \\
\text { Gravity, flotation }\end{array}$ & $\begin{array}{l}\text { Редкие, цветные металлы, } \\
\text { ФР, НП } \\
\text { Rare, non-ferrous metals, FR, } \\
\text { PP }\end{array}$ & $\begin{array}{l}\text { Mo, W, Cu, Bi, Be, Li, } \\
\text { Be, Hg, U, Rn, HП }\end{array}$ \\
\hline $\begin{array}{c}\text { Акташское (ртуть) } \\
\text { Aktashskoe (mercury) }\end{array}$ & $\begin{array}{l}\text { Обжиг, конденсация } \\
\text { Firing, condensation }\end{array}$ & $\begin{array}{l}\text { TM, HП } \\
\text { HM, PP } \\
\end{array}$ & $\mathrm{Hg}, \mathrm{As}, \mathrm{Sb}, \mathrm{Zn}, \mathrm{Cd}$ \\
\hline $\begin{array}{l}\text { Талду-Дюргун (уголь) } \\
\text { Taldu-Durgun (coal) } \\
\end{array}$ & $\begin{array}{c}\text { Без обогащения } \\
\text { Without enrichment }\end{array}$ & $\begin{array}{l}\mathrm{TM}, \mathrm{NH}_{4}^{+},(\mathrm{NO}) x, \mathrm{~S} \\
\mathrm{HM}^{\mathrm{NH}_{4}}{ }^{+},(\mathrm{NO}) x, \mathrm{~S} \\
\end{array}$ & $\mathbf{V}, \mathbf{N i}, \mathrm{Zn}, \mathrm{As}, \mathrm{Tl}, \mathrm{Cd}, \mathbf{S O}_{4}{ }^{2-}$ \\
\hline $\begin{array}{l}\text { Аэропорт (ПГС) } \\
\text { Airport (SGM) }\end{array}$ & $\begin{array}{c}\text { Классификация } \\
\text { Classification }\end{array}$ & $\begin{array}{l}\text { BB, HП } \\
\text { SS, PP }\end{array}$ & $\begin{array}{l}\mathrm{H \Pi} \\
\mathrm{PP}\end{array}$ \\
\hline
\end{tabular}

ФР - флотореагенты, НП - нефтепродукты, ирифтом выделены приоритетные индикаторы.

$F R$ - flotation reagent, PP - petroleum products, priority indicators are highlighted in font.

Менее интенсивное, но более разноплановое локальное загрязнение связано с воздействием других отраслей экономики РА. Так, предприятия сельскохозяйственной отрасли формируют специфическую ассоциацию загрязняющих веществ (табл. 1), индикаторами которой являются ортофосфаты, соединения минерального азота, органические вещества, хлорорганические инсектициды (ДДТ, ГХЦГ и их метаболиты), а также ртуть (в составе гранозана), нефтепродукты, фенолы и содержащие их гваякол, крезол и другие препараты для обработки сельхозживотных.

Предприятия лесохозяйственной отрасли загрязняют компоненты природной среды в основном нефтепродуктами (при лесозаготовке) и фенолами продуктами гниения отходов переработки древесины, а широко распространенные объекты малой тепло- энергетики (угольные котельные) содержат в выбросах токсичные оксиды углерода, азота, серы, тяжелые металлы, сажу, неорганическую и угольную пыль.

Хозяйственно-селитебные территории продуцируют более широкий спектр экотоксикантов, включающий токсичные газы, ортофосфаты, соединения минерального азота, хлориды, сульфаты, различные органические и поверхностно-активные вещества, нефтепродукты, тяжелые металлы (V, $\mathrm{Ni}, \mathrm{Cu}, \mathrm{Zn}, \mathrm{Pb}$, $\mathrm{Hg}$ и др.). Приоритетные загрязнители туротрасли представлены соединениями фосфора, азота и кальция, а автотранспорта - оксидами углерода и азота, нефтепродуктами $[10,20]$.

Известно, что почвы являются одной из наиболее информативных природных сред для изучения наложенного загрязнения как неорганической, так и орга- 
нической природы [9]. Так, особенности распределения основных для рудника «Веселый» тяжелых металлов - меди и ртути в почвах на периферии хвостохранилища золотоизвлекательной фабрики служат чуткими индикаторами специфики и интенсивности воздействия этого объекта на природную среду (рис. 4).

Другим типичным примером локального загрязнения селитебных зон является очаг остаточного загряз- нения хлорорганическим пестицидом ГХЦГ, сформированный вокруг бывшего расходного склада ядохимикатов в с. Мухор-Тархата [21]. В эпицентре этого ориентированного по розе ветров, зонально построенного очага размером $200 \times 120$ м (по изоконцентрате 1 ПДК) содержание ГХЦГ в почвах и разнотравье достигает 456 ПДК и 33 ОДК соответственно (рис. 4).
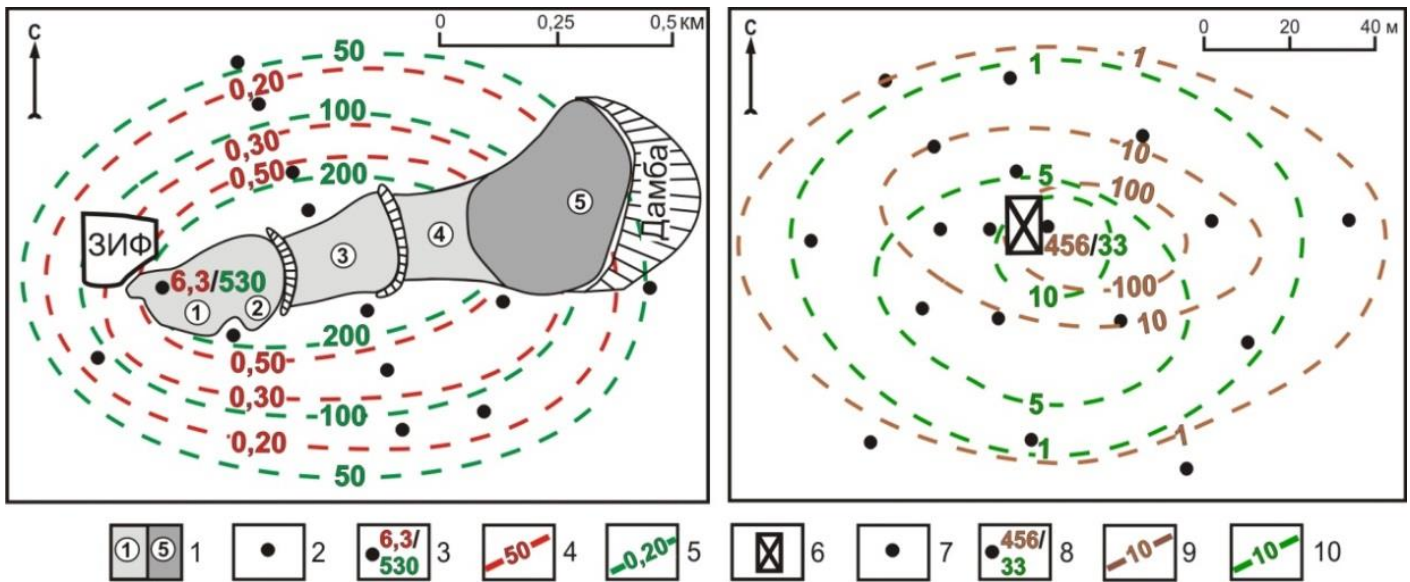

Рис. 4. Очаги поверхностного загрязнения: почв тяжелыми металлами на участке хвостохранилища ЗИФ рудника «Весельй» (слева), почв и разнотравья пестицидом ГХЦГ на участке расходного склада в с. Мухор-Тархата. 1 - прудки и их номера сухие (слева), обводненные (справа); 2 - пункты опробования почв; 3 - содержание ртути (красным) и меди (зеленым) в хвостах, мг/кг; 4, 5 - изоконцентраты ртути (4) и меди (5), мг/кг; 6 расходный склад ядохимикатов; 7 - пункты опробования почв и разнотравья; 8 - содержание ГХЦГ в почвах (коричневым) и в разнотравье (зеленым), ед. ПДК; 9, 10 - изоконцентраты ГХЦГ в почвах (9) и в разнотравье (10), ед. ПДК

Fig. 4. Sites of surface contamination: soils with heavy metals at the tailings storage site of the mine gold recovery plant "Vesely» (left), soils and grasses with HCCG pesticide at the site of a consumable warehouse in the village MukhorTarkhata. 1 - ponds and their numbers dry (left), watered (right); 2 - the points of sampling soil; 3 - content of mercury (red) and copper (green) in mill tailings, $\mathrm{mg} / \mathrm{kg} ; 4,5$ - isoconcentrates of mercury (4) and copper (5), $\mathrm{mg} / \mathrm{kg} ; 6$ expendable warehouse of pesticides; 7 - soil and grass sampling points; 8 - HCCG content in soils (brown) and in mixed grass (green), MPC units; 9, 10 - HCCG isoconcentrates in soils (9) and in different grasses (10), MPC units

Уровни содержания охарактеризованных индикаторов антропогенного загрязнения компонентов природной среды сильно варьируются, но наибольшие превышения эколого-гигиенических нормативов (ПДК, ПДУ, ОДК и др.) проявлены в очагах локального загрязнения почвенного и реже снежного покрова - основных планшетов-накопителей наложенного загрязнения. В частно- сти, в почвах промышленных зон ГДП отмечены максимальные концентрации (десятки-сотни ПДК) ртути, молибдена, вольфрама, меди и других элементов отрабатываемых месторождений (табл. 5). Для индикаторов трансграничных переносов загрязняющих веществ характерно более низкое содержание, объясняемое их рассредоточенным поступлением в почвы.

Таблица 5. Уровни содержания индикаторов химического загрязнения почв РА

Table 5. Levels of indicators of chemical contamination of RA soil

\begin{tabular}{|c|c|c|}
\hline $\begin{array}{l}\text { Загрязненные территории } \\
\text { Contaminated territory }\end{array}$ & $\begin{array}{c}\text { Основные } 3 \mathrm{~B} \\
\text { The main pollutants }\end{array}$ & $\begin{array}{c}\text { Содержание } \bar{x} / \max \text { (ед. ПДК, ед. фона*) } \\
\text { Concentration } \bar{x} / \max \text { (un. MPC, un. background*) }\end{array}$ \\
\hline $\begin{array}{c}\text { Территория РA } \\
\text { AR territory } \\
\end{array}$ & $\begin{array}{c}\text { Цезий-137 } \\
\text { Caesium-137 } \\
\end{array}$ & 45/416 Бк/кг $\left(1,5 / 13,9^{*}\right)$ \\
\hline $\begin{array}{c}\text { Районы падения ОЧ РН } \\
\text { Areas of falling SP LV } \\
\end{array}$ & $\begin{array}{l}\text { НДМГ } \\
\text { ADMG } \\
\end{array}$ & 0,15/1,5 мг/кг (1,5/15) \\
\hline $\begin{array}{c}\text { Область привноса ТМ из ВКО } \\
\text { Area of HM import from EKR }\end{array}$ & $\begin{array}{c}\text { Таллий } \\
\text { Thallium } \\
\end{array}$ & 16/140 мг/кг (8/70*) \\
\hline $\begin{array}{c}\text { Промзона Акташского ГМП } \\
\text { Industrial zone of the Aktash MME }\end{array}$ & $\begin{array}{c}\text { Ртуть } \\
\text { Mercury }\end{array}$ & 290/2000 мг/кг (138/952) \\
\hline $\begin{array}{c}\text { Промзона рудника «Калгуты» } \\
\text { Industrial zone of the «Kalguty» mine }\end{array}$ & $\begin{array}{c}\text { Молибден } \\
\text { Molybdenum } \\
\end{array}$ & 36/150 мг/кг $(3,6 / 15)$ \\
\hline $\begin{array}{c}\text { Автобаза в г. Горно-Алтайске } \\
\text { Motor depot in Gorno-Altaisk }\end{array}$ & $\begin{array}{c}\text { Свинец } \\
\text { Lead } \\
\end{array}$ & 75/300 мг/кг $(2,3 / 9,4)$ \\
\hline $\begin{array}{c}\text { Окраина с. Кызыл-Таш } \\
\text { Suburbs of the v. Kyzyl-Tash }\end{array}$ & $\begin{array}{l}\text { ГХЦГ } \\
\text { GHCG }\end{array}$ & 25/692 мг/кг (250/6920) \\
\hline
\end{tabular}


Минимальные уровни содержания индикаторов проявлены в транслирующих загрязнение природных средах - в атмосферном воздухе, речных и подземных водах, промежуточные уровни - в донных отложениях (в условиях активного водообмена) и в грунтовых водах, гидравлически связанных с поверхностью.

\section{Выводы}

На основании вышеизложенных данных можно сделать следующие выводы:

1. На территории Республики Алтай проявлен ряд региональных и локальных факторов современного и прошлого загрязнения природной среды, обусловленного трансграничными переносами экотоксикантов и воздействием местных источников локального загрязнения. Их последствия проявлены в виде различных по размерам и интенсивности очагов наложенного химического и радиохимического загрязнения.

2. Наиболее опасными для природной среды и населения региона являются разнообразные ксенобио-

\section{СПИСОК ЛИТЕРАТУРЫ}

1. Graney J.R., Edgerton E.S., Landis M.S. Using Pb isotope ratios of particulate matter and epiphytic lichens from the Athabasca Oil Sands Region in Alberta, Canada to quantify local, regional, and global $\mathrm{Pb}$ source contributions // Science of the Total Environment. - 2019. - V. 654 - P. 1293-1304.

2. Cronmiller J.G., Noble B.F. The discontinuity of environmenta effects monitoring in the Lower Athabasca region of Alberta Canada: Institutional challenges to long-term monitoring and cumulative effects management // Environmental Reviews. 2018. - V. 26. - Iss. 2. - P. 169-180.

3. Peckham M.A., Gustin M.S., Weisberg P.J. Assessment of the Suitability of Tree Rings as Archives of Global and Regional Atmospheric Mercury Pollution // Environmental Science and Technology. - 2019. - V. 53. - Iss. 7. - P. 3663-3671.

4. Integrated regional ecological risk assessment of multiple metals in the soils: A case in the region around the Bohai Sea and the Yellow Sea / Y. Shi, X. Xu, Q. Li, M. Zhang, J. Li, Y. Lu, R. Liang, X. Zheng, X. Shao // Environmental Pollution. - 2018. - V. 242. - P. 288-297.

5. Geochemical distribution of major and trace elements in agricultural soils of Castilla-La Mancha (central Spain): finding criteria for baselines and delimiting regional anomalies / S. Bravo, E. García-Ordiales, F.J. García-Navarro, J.Á. Amorós, C. Pérezde-los-Reyes, R. Jiménez-Ballesta, J.M. Esbrí, E.M. GarcíaNoguero, P. Higueras // Environmental Science and Pollution Research. - 2019. - V. 26. - Iss. 4. - P. 3100-3114.

6. Evaluation of geochemical baselines and metal enrichment facto values through high ecological quality reference points: a novel methodological approach / R. Selvaggi, B. Damianić, E. Goretti, M. Pallottini, C. Petroselli, B. Moroni, G. La Porta, D. Cappelletti // Environmental Science and Pollution Research. - 2020. - V. 27. Iss. 1. - P. 930-940

7. Geochemical and magnetic properties of sediments as pollution indicators. Case study: Suquía river, Córdoba, Argentina / L.D. Sepúlveda, K.L. Lecomte, A.I. Pasquini, E.G. Mansilla, M.A.E. Chaparro // Revista Mexicana de Ciencias Geologicas. 2019. - V. 36. - P. 183-194.

8. Savichev O.G., Paromov V.V. Chemical composition of glacia meltwaters and river waters within the Aktru river basin (Gornyi Altai) // Geography and Natural Resources. - 2013. - V. 34. № 4. - P. 364-370.

9. Индикация компонентами природной среды трансграничного переноса загрязняющих веществ на территорию Горного Алтая / Ю.В. Робертус, В.Н. Удачин, Л.П. Рихванов, А.В. Кивацкая, Р.В. Любимов, Д.В. Юсупов // Известия ТПУ. Инжиниринг георесурсов. - 2016. - Т. 327. - № 9. - С. 39-48. тики - долгоживущие техногенные радионуклиды, компоненты ракетных топлив и их производные, хлорорганические пестициды и их метаболиты, а из природных загрязнителей - радон и тяжелые металлы, особенно ртуть.

3. Информативными средами для изучения прошлых трансграничных переносов (выпадений) загрязняющих веществ на территории республики являются стратифицированные природные образования (годичные кольца деревьев, ледники, донные отложения водоемов, лишайники и др.), а текущего загрязнения - приземная атмосфера, снежный покров, в меньшей степени почвы и поверхностные воды.

4. Выявленные приоритетные индикаторы специфики и интенсивности наложенного загрязнения химическими элементами и веществами могут применяться как для установления зон воздействия региональных и локальных факторов, так и при мониторинге состояния природной среды региона.

10. Павлова К.С. Проблемы туристско-рекреационного развития Горного Алтая // Рекреационная география и инновации в туризме: Матер. II Bсерос. научн.практ. конфер. с межд. участ. - Иркутск: Изд-во Института географии им. В.Б. Сочавы СО РАН, 2014. - С. 220-222.

11. Особенности распределения химических элементов в талой воде ледника Большой Актру (Горный Алтай) / Л.П. Рихванов, Ю.В. Робертус, А.В. Таловская, Р.В. Любимов, А.Ю. Шатилов // Известия ТПУ. - 2008. - Т. 313. - № 1. - С. 97-103.

12. Страховенко В.Д., Маликова И.Н., Щербов Б.Л. Распределение ртути в компонентах окружающей среды Сибири // Химия в интересах устойчивого развития. - 2012. -Т. 20. - № 1. - С. 117-123.

13. Робертус Ю.В., Рихванов Л.П., Соктоев Б.Р. Особенности химического состава солевых отложений подземных питьевых вод Республики Алтай // Известия ТПУ. Инжиниринг георесурсов. - 2014. - Т. 324. - № 1. - С. 190-194.

14. Экологические и медико-биологические последствия воздействия ядерных испытаний на территорию и население Республики Алтай / Н.А. Мешков, Е.Г. Жиляев, Е.А. Вальцева, Л.Л. Галин. - М.: Воениздат, 1999. - 144 с.

15. Робертус Ю.В., Любимов Р.В. Факторы воздействия и экологические последствия ракетно-космической деятельности на территории Республики Алтай // Двойные технологии. 2001. - № 3. - С. 25-27.

16. Кац В.Е. Распределение таллия в компонентах окружающей среды Республики Алтай // Экология и охрана окружающей среды: Тез. докл. IV Всеросс. науч.-практ. конфер. - Рязань, 1994. - С. 139-141.

17. Сакладов А.С. Характер и масштабы влияния на окружающую среду отходов горнодобывающих предприятий Республики Алтай: автореф. дис. ... канд. геол.-минер. наук. - Томск, 2008. - 22 с.

18. Кивацкая А.В. Эколого-геохимические последствия кучного выщелачивания золота (на примере ОАО «Рудник "Веселый», Республика Алтай): автореф. дис. ... канд. геол.-минер. наук. - Томск, 2006. - 22 с.

19. Ситникова В.А. Оценка геоэкологического состояния компонентов окружающей среды на территории агломерации города Горно-Алтайска: автореф. дис. ... канд. геол.-минер. наук. Томск, 2018. - 22 с

20. Павлова К.С. Оценка геоэкологических последствий массового неорганизованного отдыха на территории Катунского рекреационного района (Республика Алтай): автореф. дис. ... канд. геогр. наук. - Барнаул, 2015. - 19 с.

21. Куликова-Хлебникова Е.Н. Хлорорганические пестициды в природных средах на территории Республики Алтай: автореф. дис. ... канд. геогр. наук. - Томск, 2013. - 19 с.

Поступила 05.08.2020 2. 


\section{Информация об авторах}

Робертус Ю.В., кандидат геолого-минералогических наук, ведущий научный сотрудник, Институт водных и экологических проблем СО РАН.

Рихванов Л.П., доктор геолого-минералогических наук, профессор отделения геологии Инженерной школы природных ресурсов, Национальный исследовательский Томский политехнический университет. 
UDC 550.84.09

\title{
CHEMICAL ELEMENTS AND SUBSTANCES - INDICATORS OF ENVIRONMENTAL POLLUTION IN THE ALTAI REPUBLIC
}

\author{
Yuriy V. Robertus 1 , \\ ariecol@mail.gorny.ru \\ Leonid P. Rikhvanov², \\ rikhvanov@tpu.ru \\ 1 Institute for Water and Environmental Problems SB RAS, \\ 1, Molodezhnaya street, Barnaul, 656038, Russia. \\ 2 National Research Tomsk Polytechnic University, \\ 30, Lenin avenue, Tomsk, 634050, Russia.
}

\begin{abstract}
Relevance of the work is determined by the need to identify and use for scientific and practical purposes priority indicators of regional and local pollution of chemical elements and substances of natural environment components on the territory of the Altai Republic.

The main aim of the research is to establish associations of chemical pollutants of the natural environment, to study the features of their behavior in natural environments and stratified natural formations, to identify priority indicators of areas and zones of imposed chemical pollution in the region.

Methods: collection, generalization and comprehensive analysis of data contained in published and stock materials of scientific and industrial organizations for the assessment of the ecological and geochemical situation on the territory of the Altai Republic and adjacent regions, processing of systematized data by methods of applied statistics.

Results. Regional and local factors of negative impact on the natural environment of the Altai Republic were described. The environmental consequences of current and past environmental pollution were given. The high information content of stratified natural formations in the study of past pollution was set. The main associations of ecotoxicants of chemical nature typical for the region were identified. The features of pollution of natural environment components during cross-border transfers of pollutants and when exposed to local sources were revealed. Natural environments that are representative for the study of superimposed pollution, as well as chemical elements and substances that are indicators of anthropogenic pollution were identified. Concentrations of priority indicators in areas of snow and soil contamination exceeding environmental and hygiene standards were established. The author made the conclusion on the greatest danger to the natural environment of the region of xenobiotics represented by technogenic radionuclides, components of rocket fuels, and organochlorine pesticides.
\end{abstract}

\section{Key words:}

Altai Republic, natural environment, sources of pollution, chemical elements, substances, indicators.

\section{REFERENCES}

1. Graney J.R., Edgerton E.S., Landis M.S. Using Pb isotope ratios of particulate matter and epiphytic lichens from the Athabasca Oil Sands Region in Alberta, Canada to quantify local, regional, and global $\mathrm{Pb}$ source contributions. Science of the Total Environment, 2019, vol. 654, pp. 1293-1304.

2. Cronmiller J.G., Noble B.F. The discontinuity of environmenta effects monitoring in the Lower Athabasca region of Alberta, Canada: Institutional challenges to long-term monitoring and cumulative effects management. Environmental Reviews, 2018 , vol. 26, Iss. 2, pp. 169-180.

3. Peckham M.A., Gustin M.S., Weisberg P.J. Assessment of the Suitability of Tree Rings as Archives of Global and Regional Atmospheric Mercury Pollution. Environmental Science and Technology, 2019, vol. 53, Iss. 7, pp. 3663-3671.

4. Shi Y., Xu X., Li Q., Zhang M., Li J., Lu Y., Liang R., Zheng X., Shao X. Integrated regional ecological risk assessment of multiple metals in the soils: A case in the region around the Bohai Sea and the Yellow Sea. Environmental Pollution, 2018, vol. 242, pp. 288-297.

5. Bravo S., García-Ordiales E., García-Navarro F.J., Amorós J.Á., Pérez-de-los-Reyes C., Jiménez-Ballesta R., Esbrí J.M., GarcíaNoguero E.M., Higueras P. Geochemical distribution of major and trace elements in agricultural soils of Castilla-La Mancha (central Spain): finding criteria for baselines and delimiting regional anomalies. Environmental Science and Pollution Research, 2019, vol. 26, Iss. 4, pp. 3100-3114.

6. Selvaggi R., Damianić B., Goretti E., Pallottini M., Petroselli C., Moroni B., La Porta G., Cappelletti D. Evaluation of geochemical baselines and metal enrichment factor values through high ecological quality reference points: a novel methodological approach. Environmental Science and Pollution Research, 2020, vol. 27, Iss. 1, pp. 930-340.

7. Sepúlveda L.D., Lecomte K.L., Pasquini A.I., Mansilla E.G., Chaparro M.A.E. Geochemical and magnetic properties of sediments as pollution indicators. Case study: Suquía river, Córdoba, Argentina. Revista Mexicana de Ciencias Geologicas, 2019, vol. 36, pp. 183-194.

8. Savichev O.G., Paromov V.V. Chemical Composition of Glacial Meltwaters and River Waters within the Aktru River Basin (Gornyi Altai). Geography and Natural Resources, 2013, vol. 34, no. 4, pp. 364-370.

9. Robertus Y. V., Udachin V.N., Rikhvanov L. P., Kivatskaya A.V., Lubimov R.V., Yjsupov D.V. Indication of the natural environment components of cross-border transport of pollutants to the territory of Gorny Altai. Bulletin of the Tomsk Polytechnic University. Geo assets Engineering, 2016, vol. 327, no. 9, pp 39-48. In Rus.

10. Pavlova K. S. Problemy turistsko-rekreatsionnogo razvitiya Gornogo Altaya [Problems of tourist and recreational development of the Gorny Altai]. Rekreatsionnaya geografiva $i$ innovatsii $v$ turizme. Materialy vtoroy Vserossiyskoy nauchno-prakticheskoy konferentsii s mezhdunarodnym uchastiem [Recreational geography and innovations in tourism. Proc. of the second allRussian scientific conference with international participation]. Irkutsk, Sochava Institute of geography SB RAS Publ. House, 2014. pp. 220-222.

11. Rikhvanov L. P., Robertus Y. V., Talovskaya A. V., Lubimov R.V., Shatilov A. Y. Features of distribution of chemical elements in melt water of the glacier Big Aktru (Gorny Altai). Bulletin of the Tomsk Polytechnic Universit y, 2008, vol. 313, no. 1, pp. 97-103. In Rus.

12. Strahovenko V.D., Malikova I.N., Shcherbov B.L. Distribution of mercury in the components of the Siberian environment. 
Chemistry for sustainable development, 2012, vol. 20, no. 1, pp. 117-123. In Rus.

13. Robertus Y.V., Rikhvanov L.P., Soktoev B.R. Features of the chemical composition of salt deposits of underground drinking water of the Altai Republic. Bulletin of the Tomsk Polytechnic University. Geo assets Engineering, 2014, vol. 324, no. 1, pp. 190-194. In Rus.

14. Meshkov N.A., Zhilyaev E.G., Valtseva E.A., Galin L.L. Ekologicheskie i mediko-biologicheskie posledstviya vozdeystviya yadernykh ispytaniy na territoriyu i naselenie Respubliki Altay [Ecological and medico-biological consequences of the impact of nuclear tests on the territory and population of the Altai Republic]. Moscow, Voenizdat Publ., 1999. 144 p.

15. Robertus Y.B., Lubimov R.V. Impact factors and environmental consequences of rocket and space activities on the territory of the Altai Republic. Double technologies, 2001, no. 3, pp 25-27. In Rus.

16. Kats V.E. Raspredelenie talliya v komponentakh okruzhayushchey sredy Respubliki Altay [Distribution of thallium in environmental components of the Altai Republic]. Ekologiya $i$ okhrana okruzhayushchey sredy. Tezisy dokladov IV Vserossiyskoy nauchno-prakticheskoy konferentsii [Ecology and environmental protection. Abstracts of the fourth all-Russian scientific and practical conference]. Ryazan, 1994. pp. 139-141.

17. Sakladov A.S. Kharakter $i$ masshtaby vlivaniva na okruzhayushchuyu sredu otkhodov gornodobyvayushchikh predpriyatiy Respubliki Altay. Avtoreferat Dis. Kand. nauk [Nature and extent of environmental impact of waste from mining enterprises in the Altai Republic. Cand. Diss. Abstract]. Tomsk, 2008. $22 \mathrm{p}$.

18. Kivatskaya A.V. Ekologo-geokhimicheskie posledstviya kuchnogo vyshchelachivaniya zolota (na primere OAO "Rudnik Vesely», Respublika Altay). Avtoreferat Dis. Kand. nauk [Ecological and geochemical consequences of heap leaching of gold (for example, JSC «Vesely Mine», Altai Republic). Cand. Diss. Abstract]. Tomsk, 2006. $22 \mathrm{p}$.

19. Sitnikova V.A. Otsenka geoekologicheskogo sostoyaniya komponentov okruzhayushchey sredy na territorii aglomeratsii goroda Gorno-Altayska. Avtoreferat Dis. Kand. nauk [Assessment of the geo-ecological state of environmental components on the territory of the Gorno-Altaisk agglomeration. Cand. Diss. Abstract]. Tomsk, 2018. 22 p.

20. Pavlova K.S. Otsenka geoekologicheskikh posledstviy massovogo neorganizovannogo otdykha na territorii Katunskogo rekreatsionnogo rayona (Respublika Altay). Avtoreferat Dis. Kand. nauk. [Assessment of geo-ecological consequences of mass unorganized recreation on the territory of the Katun recreational district (Altai Republic). Cand. Diss. Abstract]. Barnaul, 2015. 19 p.

21. Kulikova-Khlebnikova E.N. Khlororganicheskie pestitsidy $v$ prirodnykh sredakh na territorii Respubliki Altay. Avtoreferat Kand. nauk [Organochlorine pesticides in natural environments on the territory of the Republic. of Altai. Cand. Diss. Abstract]. Tomsk, 2013. 19 p.

Received: 5 August 2020.

Information about the authors

Yuriy V. Robertus, Cand. Sc., leading researcher, Institute for Water and Environmental Problems SB RAS.

Leonid P. Rikhvanov, Dr. Sc., professor, National Research Tomsk Polytechnic University. 